\title{
Melhoria da Qualidade da Água no Estado de Santa
}

Water Quality Improvement in the State of Santa Catarina

Mejora de la Calidad del Agua en el Estado de Santa Catarina

\author{
Gilmar de Almeida Gomes \\ Professor Doutor, UDESC, Brasil. \\ gilmargomess@yahoo.com.br
}

Naraiana Bovenschulte de Jesus Acadêmica de Engenharia de Alimentos, UDESC, Brasil. naraboven@gmail.com

Carolina Franchini Acadêmica de Engenharia de Alimentos, UDESC, Brasil. carolfran18@hotmai.com 


\section{Periádica Eletrónica \\ (1)}

\section{RESUMO}

O Estado de Santa Catarina tem como característica elevada população rural, onde os recursos hídricos estão sofrendo várias formas de contaminação, podendo gerar impactos tanto nas águas subterrâneas como nas superficiais. O objetivo do presente estudo foi avaliar a qualidade da água do perímetro rural de cidades da região Oeste, com enfoque maior em Pinhalzinho, Meio Oeste e Norte catarinense. Foram feitas análises microbiológicas (coliformes totais e termotolerantes) e físico-químicas (cloreto, $\mathrm{pH}$ e sólidos totais) segundo métodos propostos pela FUNASA (Fundação Nacional da Saúde). Os resultados mostram que todas as águas possuem algum parâmetro fora dos padrões estabelecidos pelo CONAMA (Conselho Nacional de Meio Ambiente): na região Meio Oeste o teor de sólidos totais apresentou-se acima do padrão estabelecido na cidade 9 e na região Norte as cidades 1 e 6 apresentaram valores de $\mathrm{pH}$ abaixo do estabelecido por esta legislação. Os coliformes totais e termotolerantes foram detectados em todas as regiões analisadas.

PALAVRAS-CHAVE: Perímetro rural. Qualidade da água. Meio ambiente.

\section{SUMMARY}

The state of Santa Catarina is characterized by high rural population, where water resources are suffering from various forms of pollution, can have an impact both in groundwater and in surface. The aim of this study was to evaluate the water quality of rural perimeter of the western region cities, with greater focus on Pinhalzinho, Middle East and North Santa Catarina. Microbiological analyzes were performed (total and fecal coliforms) and physicochemical (chlorine, $\mathrm{pH}$ and total solids) using methods proposed by FUNASA (National Health Foundation). The results show that all waters have some parameter outside the standards set by CONAMA (National Environment Council): the region Midwest the total solids content is presented above the standard established in the city 9 and in the North cities 1 and 6 showed pH values below established by this legislation. The total and fecal coliforms were detected in all analyzed regions.

KEY WORDS: Rural perimeter. Water quality. Environment.

\section{RESUMEN}

El estado de Santa Catarina se caracteriza por una alta población rural, donde los recursos hídricos sufren de diversas formas de contaminación, puede tener un impacto tanto en aguas subterráneas y en superficie. El objetivo de este estudio fue evaluar la calidad del agua del perímetro rural de las ciudades región occidental, con mayor énfasis en Pinhalzinho, Oriente Medio y el Norte de Santa Catarina. Los análisis microbiológicos se llevaron a cabo (coliformes totales y fecales) y físico-químicos (cloro, $\mathrm{pH}$ y sólidos totales) usando métodos propuestos por (Fundación Nacional de la Salud) Funasa. Los resultados muestran que todas las aguas tienen algún parámetro fuera de las normas establecidas por la CONAMA (Consejo Nacional de Medio Ambiente): la región del Medio Oeste del contenido total de sólidos se presenta por encima de la norma establecida en la ciudad 9 y en las ciudades del Norte 1 y 6 mostraron valores de pH por debajo establecido por esta legislación. Los coliformes totales y fecales se detectaron en todas las regiones analizadas.

PALABRAS CLAVE: Perímetro rural. La calidad del agua. Medio ambiente. 


\section{INTRODUÇÃO}

A água é essencial à saúde dos seres vivos. Para consumo humano, deve ser limpa e livre de quaisquer patógenos, impurezas e de qualquer tipo de contaminação que cause danos à saúde, conferindo-a como potável. (BRASIL, 2006).

No meio rural, a água é utilizada para inúmeras finalidades, destacando-se: o uso da água para irrigação e dessedentação animal, práticas agrícolas e produção de animais para abate, entre outros. (Vilas, 2003). Dentre os diversos usos da água no meio rural, destaca-se o uso para cosumo humano.

A água no meio rural normalmente não recebe a mesma atenção daquela do meio urbano, esse fato ocorre em função de que, no meio urbano existe um maior controle da qualidade da água pelo órgão distribuidor. No meio rural esse controle é frequentemente negligenciado. (JESUS, 2014). Desta forma é fundamental ampliar o monitoramento da qualidade da água no meio rural, onde grande parte da população não é abastecida por empresas de saneamento e ela geralmente é obtida por sistemas individuais e alternativos de abastecimento, sendo mais comuns os poços artesianos, reservatórios comunitários, entre outros. (CARDOSO,2012).

Convém salientar que grande parte desses sistemas são vulneráveis à contaminação por problemas estruturais relacionados à sua construção, distribuição e também por não possuírem monitoramento adequado de sua qualidade, sendo que a poluição decorrida de atividades rurais representa um dos mais importantes contribuintes para a contaminação de corpos hídricos. Além disso, diversas doenças podem ser transmitidas por água contaminada como cólera, hepatite e diarreias. Sendo assim, manter-se a qualidade da água é uma questão de saúde pública. (FRANCHINI, 2015).

A adoção de medidas para a conservação e o uso racional da água, a utilização de fontes alternativas e a criação de políticas públicas de educação ambiental para a conscientização da população sobre a necessidade de se preservar esse recurso natural são de fundamental importância para assegurar a disponibilidade a atual e as futuras gerações. (SOUZA, 2012).

O teor de cloreto é um indicador de poluição por esgoto doméstico, podendo conferir á água sabor salino e uma propriedade laxativa (RICHTER, NETTO, 1991, p. 33). No caso da presença em água do perímetro rural, pode indicar a presença de adubação com dejetos animais. (BULEGON, 2013).

O teor de sólidos totais na água refere-se à quantidade de matéria suspensa ou dissolvida, podendo afetar negativamente sua qualidade, seu excesso pode causar alterações no sabor e provocam elevada turbidez. A medida de $\mathrm{pH}$ também é um parâmetro de qualidade da água e deve apresentar valores estabelecidos por legislação.

Os coliformes são bactérias que normalmente residem nos intestinos dos animais superiores e a sua presença na água indica a possibilidade de contaminação por esgoto doméstico. (RICHTER; NETTO, 1991, p. 37). No caso da presença na água do perímetro rural, pode indicar a presença de adubação com dejetos de animais. (BULEGON, 2013).

A bactéria Escherichia coli é o principal indicador de contaminação fecal, pois a presença desse microorganismo mostra que a água pode ter recebido elevada carga fecal, ocasionando a 
deterioração da qualidade microbiológica dessa água e, como consequência, pode trazer riscos à saúde de quem a consome.

O estado de Santa Catarina tem como característica uma elevada população rural, e a maior parte do abastecimento de água nesse perímetro é realizado por reservatórios comunitários, o que faz do tratamento dessas águas imprescindível. (JESUS, 2014).

O município de Pinhalzinho, pertencente à região Oeste de Santa Catarina possui muitas nascentes de água doce espalhadas por toda a sua extensão (ANTUNES, 2009) e também possui elevada população rural quando comparada com a média nacional.

\section{OBJETIVO}

O objetivo do presente estudo é analisar a qualidade da água dos reservatórios comunitários situados na zona rural do Estado de Santa Catarina, através de análises microbiológicas (coliformes totais e termotolerantes) e físico-químicas $(\mathrm{pH}$, sólidos totais e cloreto). Na região Oeste, estudar as variações dos parâmetros físico químicos e microbiológicos com o tempo de monitoramento. Comparar o comportamento de cada parâmetro em função da região.

\section{METODOLOGIA}

Foram coletadas amostras de água do perímetro rural das regiões Oeste, Norte e Meio Oeste do Estado de Santa Catarina.

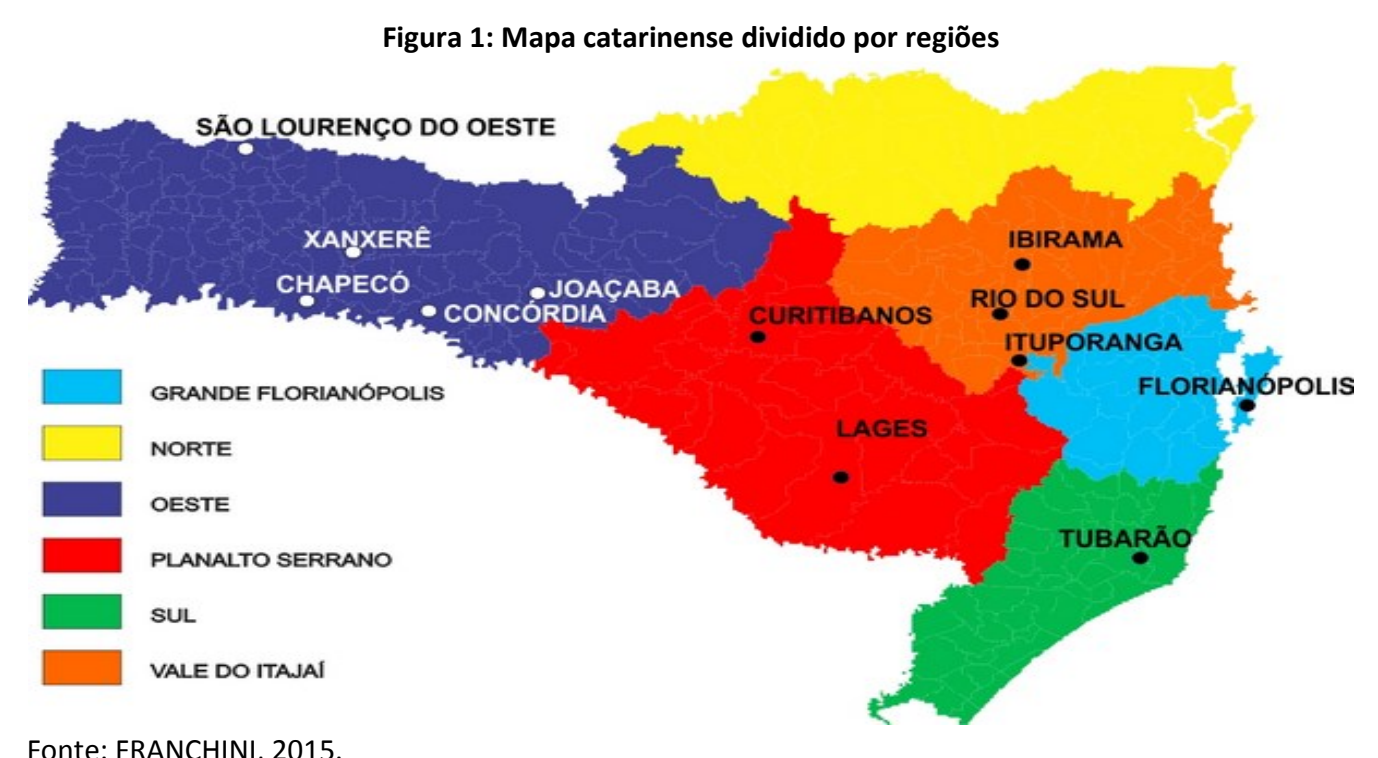

Na cidade de Pinhalzinho, localizada no Oeste do Estado, foram coletadas amostras de água nos anos de 2013, 2014 e 2015. 
Figura 2: Reservatórios Comunitários da Cidade de Pinhalzinho - SC

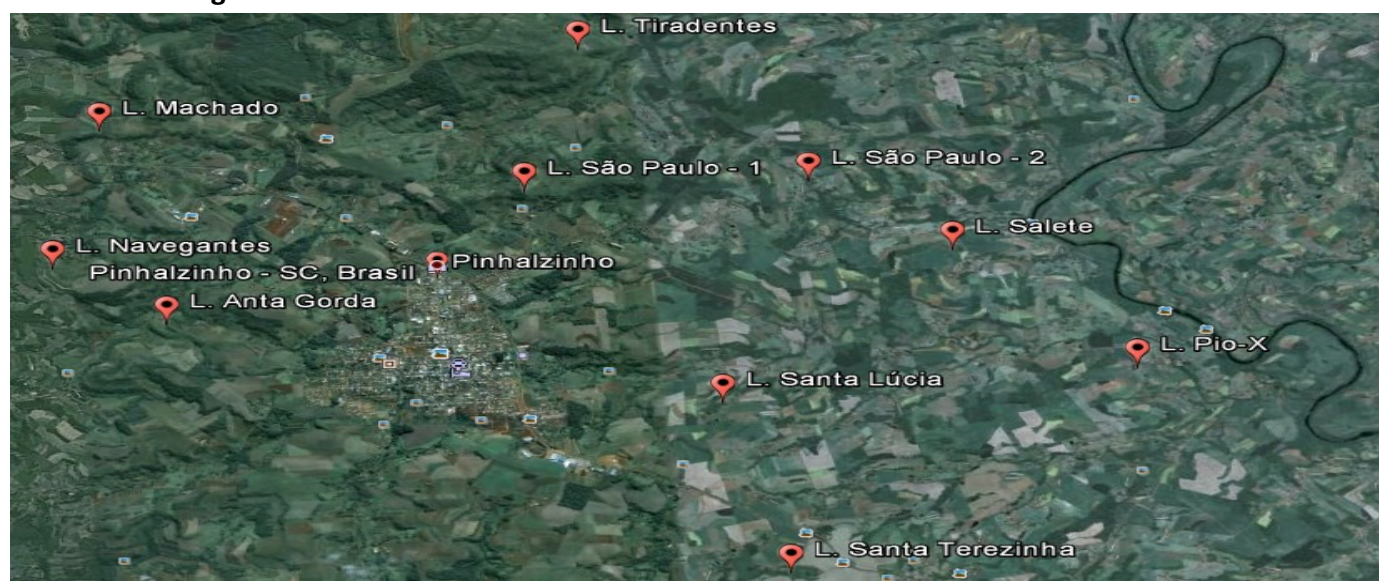

Fonte: BULEGON, 2013.

Essas amostras foram coletadas em frascos de vidro esterilizados de $500 \mathrm{~mL}$ e armazenadas em caixas de isopor e então transportadas ao laboratório da Universidade do Estado de Santa Catarina onde as análises microbiológicas e físico químicas foram realizadas. Para as determinações de cloreto, sólidos totais, coliformes totais e termotolerantes seguiram-se os métodos descritos pelo Manual Prático de Análise de Água da FUNASA (Fundação Nacional de Saúde). Na medida de $\mathrm{pH}$ foi utilizado o pHmetro Q400 MT da marca QUIMIS.

As figuras 3, 4 e 5 foram feitas utilizando-se o programa Microsoft Excel ${ }^{\circledR}$.

A qualidade da água é definida pelo Conselho Nacional de Meio Ambiente (CONAMA), que dispões sobre os parâmetros adequados para água na Resolução n. 20 de 1986.

\section{RESULTADOS E DISCUSSÃO}

Na Tabela 1 abaixo, são apresentados os resultados obtidos para a análise físico química de cloreto para as águas das regiões Meio Oeste, Oeste e Norte catarinense. 
Tabela 1: Teores de cloreto nas águas das regiões Meio Oeste, Oeste e Norte

\begin{tabular}{|c|c|c|c|}
\hline \multicolumn{4}{|c|}{ Cloreto (mg/L) } \\
\hline Cidades & Meio Oeste & Oeste & Norte \\
\hline Cidade 1 & 4,40 & 2,84 & 11,54 \\
\hline Cidade 2 & 8,70 & 55,03 & 3,46 \\
\hline Cidade 3 & 6,50 & 3,46 & 6,75 \\
\hline Cidade 4 & 6,14 & 3,91 & 6,48 \\
\hline Cidade 5 & 12,78 & 3,73 & 17,75 \\
\hline Cidade 6 & 7,10 & 4,54 & 20,95 \\
\hline Cidade 7 & 17,23 & 3,73 & - \\
\hline Cidade 8 & 8,34 & 4,08 & - \\
\hline Cidade 9 & 6,92 & - & - \\
\hline Cidade 10 & 5,51 & - & - \\
\hline Cidade 11 & 5,62 & - & - \\
\hline PADRÃO & \multicolumn{3}{|c|}{250 (mg/L) } \\
\hline
\end{tabular}

As diferenças nos teores de cloreto observadas de uma região à outra foram pequenas e nenhuma amostra ultrapassou o limite estabelecido pela legislação CONAMA, que é de 250 $\mathrm{mg} / \mathrm{L}$. Abaixo, na Figura 3, é apresentado o gráfico que mostra a variação de cloreto nas regiões avaliadas.

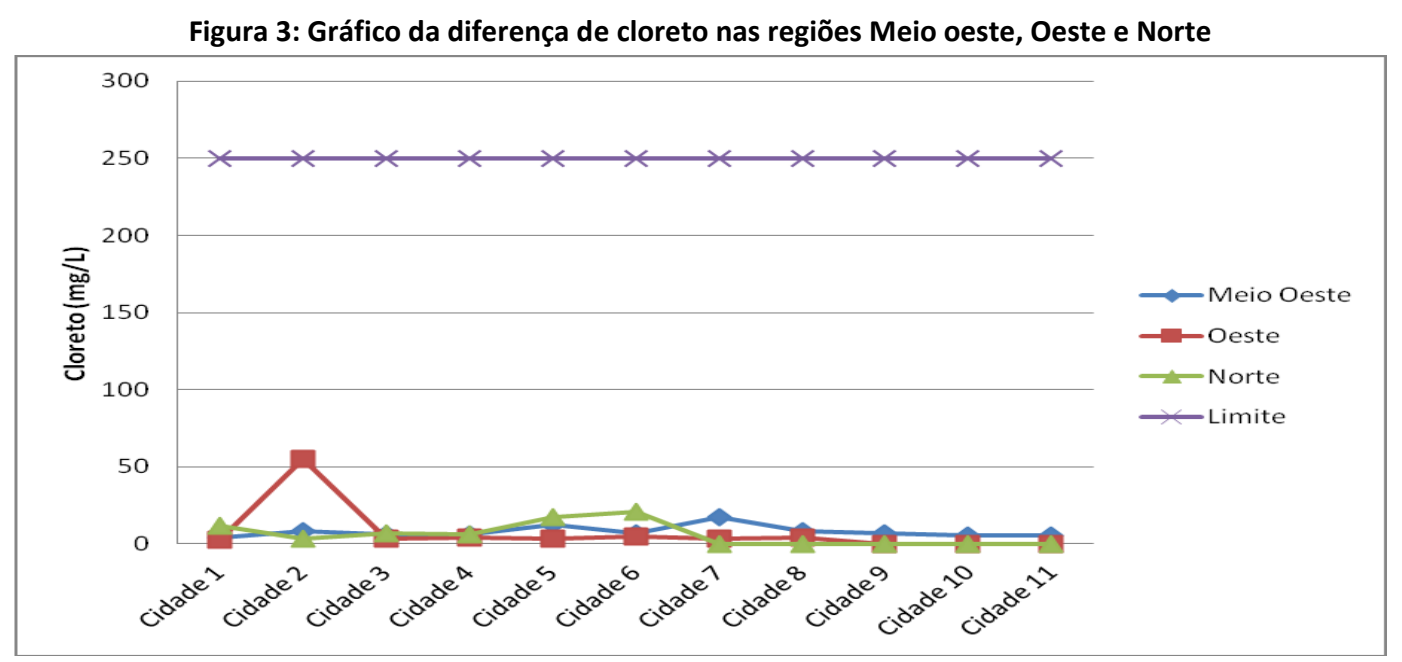

A Tabela 2 abaixo mostra os resultados obtidos para análise físico química de $\mathrm{pH}$ das águas das regiões Meio Oeste, Oeste e Norte catarinense. 


\section{$+$}

Tabela 2: Medidas de pH nas águas das regiões Meio Oeste, Oeste e Norte

\begin{tabular}{c|c|c|c}
\hline \multicolumn{7}{|c}{ pH } \\
\hline Cidades & Meio Oeste & Oeste & Norte \\
\hline Cidade 1 & 6,33 & 6,75 & 5,47 \\
\hline Cidade 2 & 6,29 & 7,42 & 6,98 \\
\hline Cidade 3 & 6,73 & 7,98 & 6,74 \\
\hline Cidade 4 & 7,21 & 7,42 & 6,41 \\
\hline Cidade 5 & 6,97 & 7,35 & 6,77 \\
\hline Cidade 6 & 7,02 & 7,53 & 5,01 \\
\hline Cidade 7 & 8,87 & 7,65 & - \\
\hline Cidade 8 & 7,56 & 6,69 & - \\
\hline Cidade 9 & 7,92 & - & - \\
\hline Cidade 10 & 9,23 & - & - \\
\hline Cidade 11 & 7,31 & - & \\
\hline PADRÃO & & $6,0 / 9,5$ & \\
\hline
\end{tabular}

Estudos médicos apontam a importância do consumo de água com pH alcalino, para dessa forma neutralizar a acidez no organismo proveniente do consumo de alimentos ácidos. $\mathrm{Na}$ medida de pH, a maior variação entre os resultados foi na região Meio Oeste, de 6,29 até 9,23, porém nessa região, assim como na região Oeste, nenhuma amostra apresentou-se fora da legislação estabelecida pelo CONAMA, que determina que o pH deve estar entre 6,0 á 9,5. Já na região Norte, observa-se que em duas cidades o valor de $\mathrm{pH}$ foi abaixo que o estabelecido. A Figura 4 mostra a variação de pH na região Norte.

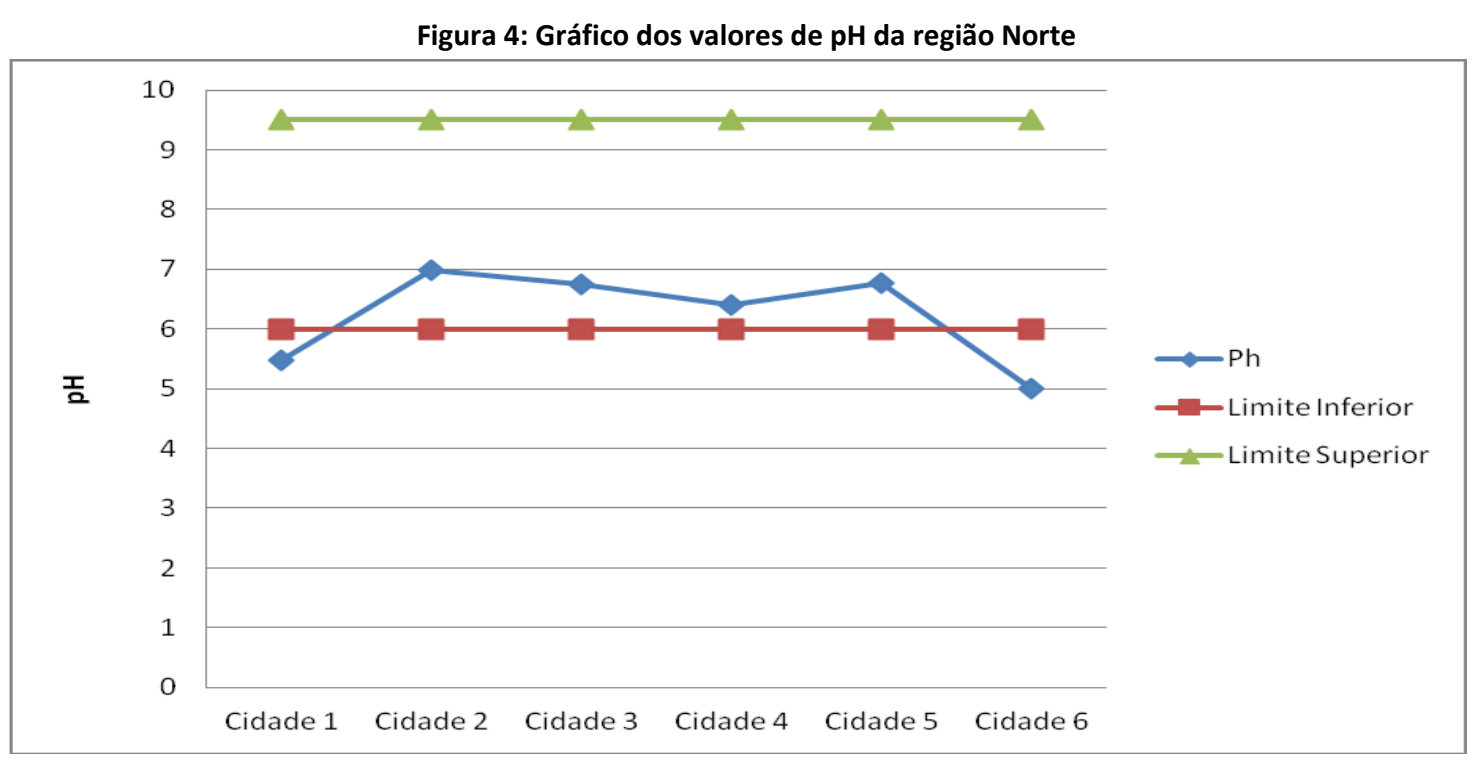

A Tabela 3 abaixo apresenta os resultados obtidos para a análise físico química de sólidos totais para as águas das regiões Meio Oeste, Oeste e Norte. 
Tabela 3: Teores de sólidos totais nas águas das regiões Meio oeste, Oeste e Norte

\begin{tabular}{c|c|c|c}
\hline \multicolumn{5}{c}{ Sólidos Totais (mg/L) } \\
\hline Cidades & Meio Oeste & Oeste & Norte \\
\hline Cidade 1 & 166 & 1,40 & 60,0 \\
\hline Cidade 2 & 310 & 15,70 & 72,0 \\
\hline Cidade 3 & 316 & 8,70 & 84,0 \\
\hline Cidade 4 & 128 & 5,10 & 110,0 \\
\hline Cidade 5 & 402 & 7,40 & 120,0 \\
\hline Cidade 6 & 384 & 1,20 & 68,0 \\
\hline Cidade 7 & 425 & 10,20 & - \\
\hline Cidade 8 & 202 & 6,40 & - \\
\hline Cidade 9 & 530 & - & - \\
\hline Cidade 10 & 322 & - & - \\
\hline Cidade 11 & 288 & - & \\
\hline PADRÃO & & $\mathbf{5 0 0}$ (mg/L) & \\
\hline & & & \\
\hline
\end{tabular}

Segundo o CONAMA, a quantidade máxima de sólidos totais permitida é de $500 \mathrm{mg} / \mathrm{L}$, sendo assim, nenhuma cidade da região Oeste e Norte apresentaram-se fora do padrão. Apenas a cidade 9, na região Meio Oeste, apresentou valor superior ao máximo estabelecido, conforme mostrado na Figura 5.

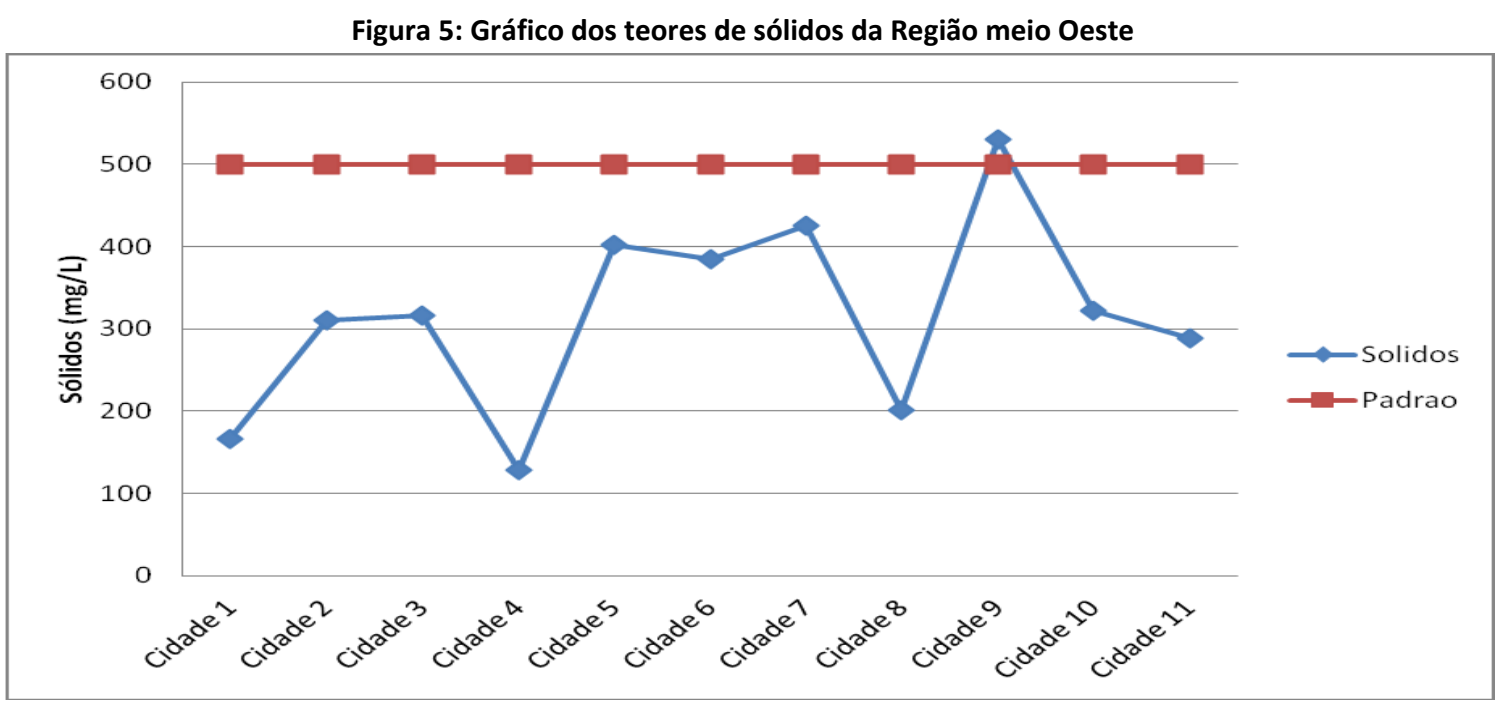

A Tabela 4 abaixo apresenta os resultados obtidos para as análises microbiológicas de coliformes totais e termotolerantes para as regiões Meio Oeste, Oeste e Norte. 
Tabela 4: Resultados microbiológicos das águas do Meio Oeste, Oeste e Norte

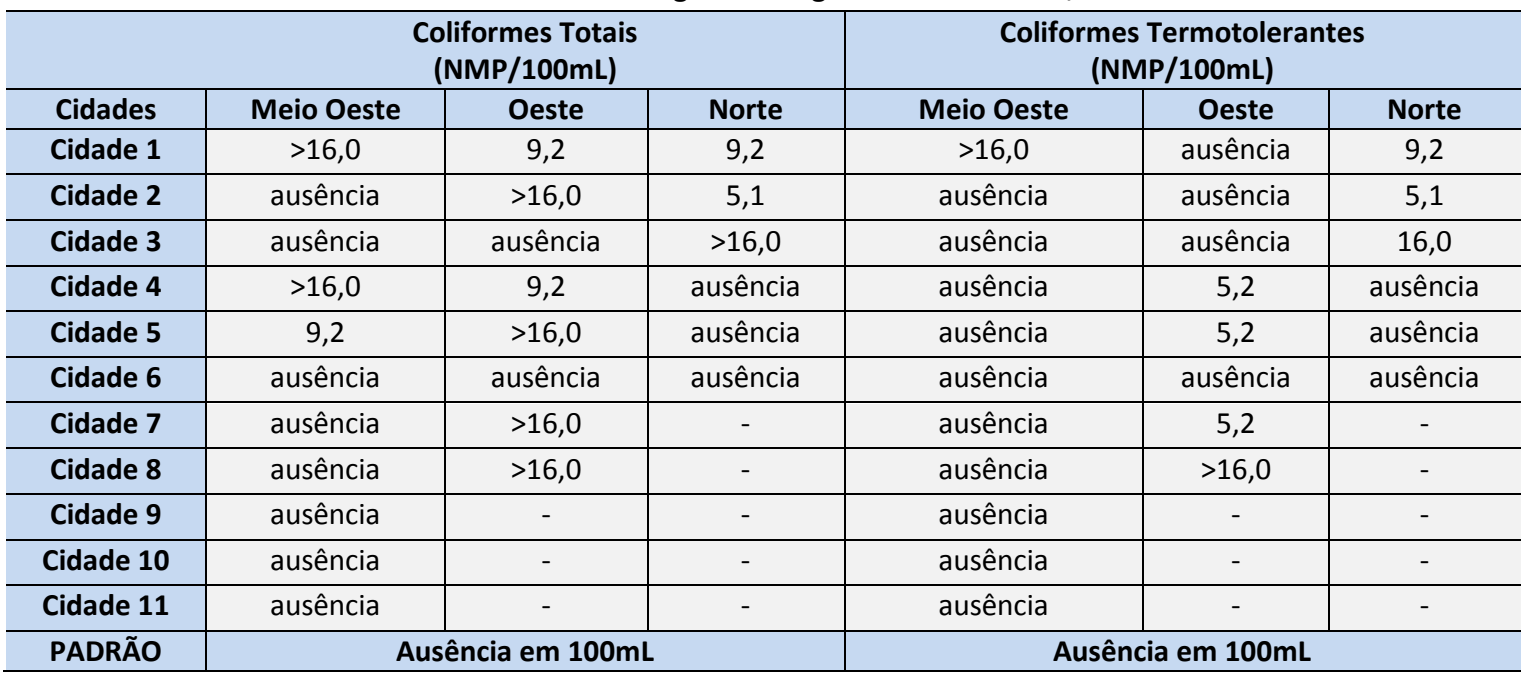

Conforme a legislação CONAMA, a água para ser considerada potável deve apresentar ausência de coliformes totais e termotolerantes em $100 \mathrm{~mL}$ de água. Quando observada a Tabela 4, percebe-se que todas as regiões apresentaram cidades com esse parâmetro fora do padrão estabelecido, pois, mesmo na região Norte, região esta que apresentou os melhores resultados para os parâmetros microbiológicos, três cidades apresentaram a presença desses indicadores de contaminação. $O$ fato de todas as regiões apresentarem a presença de coliformes totais $\mathrm{e}$ termotolerantes se deve ao fato de que, no perímetro rural, a prática agrícola, a adubação do solo com dejetos animais e a própria criação de gado próximo aos poços, que provavelmente não são encamisados de maneira correta, faz com que aumente a contaminação da água por essas bactérias. Na região Meio Oeste e Oeste, a presença desses indicadores é maior quando comparada à região Norte, devido à economia exercida nessas regiões, que é voltada ao agronegócio.

\section{Avaliação da qualidade da água de reservatórios comunitários do perímetro rural de Pinhalzinho - SC}

Na região Oeste o monitoramento é realizado com uma maior periodicidade usando como modelo a cidade de Pinhalzinho. Os resultados obtidos para as análises físico químicas e microbiológicas nos anos de 2013, 2014 e 2015 são apresentados nas Tabelas 5 e 6 abaixo. 
Tabela 5: resultados obtidos para as análises físico químicas realizadas nas águas de Pinhalzinho- SC

\begin{tabular}{|c|c|c|c|c|c|c|c|c|c|}
\hline \multirow[b]{2}{*}{ Reservatórios } & \multicolumn{3}{|c|}{ Cloreto (mg/L) } & \multicolumn{3}{|c|}{$\mathrm{pH}$} & \multicolumn{3}{|c|}{ Sólidos Totais (mg/L) } \\
\hline & 2013 & 2014 & 2015 & 2013 & 2014 & 2015 & 2013 & 2014 & 2015 \\
\hline Reservatório 1 & 8,51 & 3,37 & 2,84 & 5,93 & 5,94 & 6,75 & 1,0 & 3,0 & 1,4 \\
\hline Reservatório 2 & 80,83 & 5,50 & 55,03 & 5,88 & 7,59 & 7,42 & 1,5 & 9,0 & 15,7 \\
\hline Reservatório 3 & 9,22 & 5,68 & 3,46 & 5,71 & 6,42 & 7,98 & 5,9 & 3,0 & 8,7 \\
\hline Reservatório 4 & 9,93 & 6,04 & 3,91 & 7,83 & 7,17 & 7,42 & 5,4 & 6,0 & 5,1 \\
\hline Reservatório 5 & 8,50 & 5,15 & 3,73 & 7,90 & 7,41 & 7,35 & 1,8 & 8,0 & 7,4 \\
\hline Reservatório 6 & 9,22 & 6,04 & 4,54 & 7,50 & 7,37 & 7,53 & 8,0 & 20,0 & 1,2 \\
\hline Reservatório 7 & 7,80 & 6,04 & 3,73 & 7,67 & 7,54 & 7,65 & 3,5 & 7,6 & 10,2 \\
\hline Reservatório 8 & 8,95 & 3,02 & 4,08 & 8,49 & 8,36 & 5,69 & 1,4 & 9,0 & 6,4 \\
\hline PADRÃO & \multicolumn{3}{|c|}{250} & \multicolumn{3}{|c|}{$6,0 / 9,5$} & \multicolumn{3}{|c|}{500} \\
\hline
\end{tabular}

Tabela 6: Resultados obtidos para as análises microbiológicas realizadas nas água de Pinhalzinho - SC

\begin{tabular}{|c|c|c|c|c|c|c|}
\hline \multirow[b]{2}{*}{ Reservatórios } & \multicolumn{3}{|c|}{$\begin{array}{l}\text { Coliformes Totais } \\
\text { (NMP/100mL) }\end{array}$} & \multicolumn{3}{|c|}{$\begin{array}{l}\text { Coliformes Termotolerantes } \\
\text { (NMP/100mL) }\end{array}$} \\
\hline & 2013 & 2014 & 2015 & 2013 & 2014 & 2015 \\
\hline Reservatório 1 & 16,0 & $>16,0$ & 9,2 & 9,2 & 2,2 & ausência \\
\hline Reservatório 2 & 16,0 & ausência & $>16,0$ & 9,2 & ausência & ausência \\
\hline Reservatório 3 & 16,0 & 5,1 & ausência & 5,1 & ausência & ausência \\
\hline Reservatório 4 & ausência & 16,0 & 9,2 & ausência & ausência & 5,2 \\
\hline Reservatório 5 & $>16,0$ & 16,0 & $>16,0$ & 5,2 & ausência & 5,2 \\
\hline Reservatório 6 & 16,0 & $>16,0$ & ausência & 9,2 & ausência & ausência \\
\hline Reservatório 7 & 16,0 & $>16,0$ & $>16,0$ & 9,2 & 9,2 & 5,2 \\
\hline Reservatório 8 & $>16,0$ & ausência & $>16,0$ & $>16,0$ & ausência & $>16,0$ \\
\hline PADRÃO & \multicolumn{3}{|c|}{ ausência } & \multicolumn{3}{|c|}{ ausência } \\
\hline
\end{tabular}

Fica evidente a melhora da qualidade nas águas dos reservatórios comunitários. Os reservatórios 1, 2 e 3 que apresentavam valores de pH abaixo do pressuposto em legislação, adequaram-se a ela. $\mathrm{O}$ teor de sólidos foi reduzido na maioria dos reservatórios durante $\mathrm{o}$ monitoramento. Os valores de cloreto mantiveram-se dentro dos padrões estabelecidos pelo CONAMA. No que diz respeito à contaminação microbiológica, essa também diminuiu na maioria dos reservatórios, sendo que os reservatórios 3 e 6 passaram a apresentar ausência de coliformes totais e os reservatórios 1, 2, 3 e 6 ausência de coliformes termotolerantes. Essa melhora é decorrente do tratamento realizado pelos responsáveis, através do incentivo e orientações dadas pelo programa.

\section{CONCLUSOES}

Os resultados deste estudo evidenciam que, conforme pressuposto anteriormente a água para consumo humano no perímetro rural não recebe o mesmo tratamento que o perímetro urbano. Através dos resultados das análises de água dos reservatórios comunitários do 
perímetro rural das Regiões Oeste, Meio Oeste e Norte de Santa Catarina, conclui-se que todas as fontes apresentam pelo menos um parâmetro que as tornam impróprias para o consumo humano, segundo pressupõem a legislação CONAMA. O que justifica a qualidade inferior nas regiões Oeste e Meio Oeste é a economia voltada ao agronegócio. Convém ressaltar que a ação sistemática - análise, tratamento e treinamento dos responsáveis pelos reservatórios comunitários - na melhoria da qualidade da água na região Oeste mostraram resultados positivos, como evidenciam as tabelas 5 e 6 . Sendo assim, faz-se necessário uma abordagem sistêmica para que os poderes públicos resolvam a questão da qualidade da água no perímetro rural: análise, tratamento e treinamento contínuo dos responsáveis pelos reservatórios comunitários de forma ininterrupta para gerar uma conscientização e cultura da necessidade de ter-se água com qualidade.

\section{AGRADECIMENTO}

À Universidade do Estado de Santa Catarina - UDESC e às prefeituras municipais das cidades pertencentes às regiões abrangidas.

\section{REFERÊNCIAS BIBLIOGRÁFICAS}

ANTUNES, S. A., VALCAREGGI, G. A., GOMES, G. A., ROBAZZI, W. S. Estudos do fluxo químico hidrológico na região Oeste de santa Catarina, 2009.

BRASIL. Instituto da Água, 2006. Disponível em: <http://www.inag.pt> acesso em 02/05/2016.

BULEGON. R; ZAMIANI,A. GOMES, G.D.A; Periódico eletrônico. Fórum Nacional da Alta Paulista, v. 08, n.02, 2012.

CAMPONOGARA, S. Saúde e meio ambiente na contemporaneidade: O necessário resgate do legado de Florence Nightingale. Ed. Esc. Anna Nery, 2012, v.16, n.1, p.178-184.

CARDOSO, Lulli Pitone; Dubow, Michele; at. al Problemática da qualidade da água consumida em uma escola da zona rural do município de Cerrito Alegre - RS, 2012.

CLARKE, R.; KING, J. 0 atlas da água. São Paulo: Publifolha, 2005. 128 p.

CONSELHO NACIONAL DO MEIO AMBIENTE - CONAMA. Resolução no $\mathbf{3 5 7}$ de 17 de março de 2005. Dispõe sobre a classificação dos corpos de água e diretrizes ambientais para o seu enquadramento, bem como estabelece as condições e padrões de lançamento de efluentes. Ministério do Meio Ambiente. 2005.

FRANCHINI, C., GOMES, G. A., JESUS, N. B. Qualidade da água do Estado de Santa Catarina, 2015.

FUNASA. Fundação Nacional de saúde. Manual Prático de Análise de Àgua. Acessoria de comunicação e educação em saúde. Brasília/DF. Disponível em:www.funasa.gov.br Acesso em 02/05/2016.

JESUS, N. B., GOMES, G.A., BULEGON, R., FRANCHINI, C. Controle da Qualidade da água do Perímetro Rural do Oeste de SC, 2014. 
PERDOMO, Daiana Marin Xarão; CASTRO, Fabiane Picini; et. al Avaliação da qualidade da água consumida na zona rural da região centro do estado do Rio Grande do Sul, 2006, vol. 18, n. 9/10.

RICHTER, Carlos T. Tratamento de água: Tecnologia Atualizada. Editora Edgard Blucher. São Paulo 2003.Disponível em:www.scielo.com.br .Acesso em 04/05/2016.

SOUZA, Simonia Aparecida de. Água juridicamente sustentável: Um estudo sobre a educação ambiental como instrumento de efetividade do programa de conservação e uso racional da água nas edificações de Curitiba/PR. Revista meio ambiente e sustentabilidade. Vol 1. N¹. 2012. Disponível em: www.scielo.com.br Acesso em 04/05/2016.

VILAS, Andres Troncoso. Racionalização do uso da água no meio rural, CGEE, Brasília, p.94, 2003. 